\title{
Sectoral shocks and home substitution
}

\author{
Alessio Moro $^{\text {a,* }}$, Satoshi Tanaka ${ }^{\text {b }}$ \\ a University of Cagliari, Italy \\ ${ }^{\mathrm{b}}$ University of Queensland, Australia
}

\section{H I G H L I G H T S}

- We study the effect of sectoral shocks on sectoral consumption shares.

- The effect on a share depends on substitutability of the good with home production.

- A shock to manufacturing (non-substitutable) largely affects consumption shares.

- A shock to services (home-substitutable) has a mild effect on consumption shares.

\section{A R T I C L E I N F O}

\section{Article history:}

Received 28 January 2019

Received in revised form 27 March 2019

Accepted 19 April 2019

Available online 7 May 2019

\section{JEL classification:}

E21

E32

L16

Keywords:

Sectoral shocks

Home production

Services sector

\begin{abstract}
A B S T R A C T
We show that the effect of a sectoral shock on the composition of sectoral shares crucially depends on whether the goods produced in the sector are home-substitutable or not. When a productivity shock hits the market sector that produces non-home-substitutable goods (e.g. manufacturing goods), the shock largely affects the composition of consumption shares of market sectors. On the other hand, when a shock hits the market sector that produces home-substitutable goods (e.g. service goods), relocation in shares mainly occurs between the sector and the home sector. We compare our results to those of the traditional three-sector model without a home sector, and show that the missing of the home substitution effects predicts completely different implications for the response of consumption shares to sectoral shocks.
\end{abstract}

(C) 2019 Published by Elsevier B.V.

\section{Introduction}

The home production sector was recently introduced in several applications of multi-sector models (Rogerson, 2008; Ngai and Pissarides, 2008; Ngai and Petrongolo, 2017; Rendall, 2018). This sector creates a margin, which is typically not observed in national accounts, that can affect the market economy to a large extent. Here we study the effects of supply shocks, modeled as changes in prices in a partial equilibrium setting, in shaping the business cycle of consumption shares. When there is a supply shock on goods that have no home production counterparts, the adjustment in consumption shares is substantial, as the margin of adjustment is among goods produced in the market. On the other hand, if the shock is on goods (or services) with home produced

\footnotetext{
This research was supported by a grant-in-aid from Zengin Foundation for Studies on Economics and Finance. The usual disclaimers apply.

* Corresponding author.

E-mail addresses: amoro@unica.it (A. Moro), s.tanaka@uq.edu.au (S. Tanaka).
}

counterparts, the relevant margin of adjustment is between market and home services. In this case, market consumption shares should be little affected by this shock.

To provide a quantitative assessment of the effect of supply shocks on consumption shares, a model that can fit the longrun pattern of structural change, including home production, is needed. Typically, the difficulty encountered in doing this is that data on home production are scarce. Therefore, the papers in the previous literature calibrate the model indirectly (Benhabib et al., 1991; Greenwood and Hercowitz, 1991; McGrattan et al., 1997). An exception is the recent paper by Moro et al. (2017), who estimate a structural change model with home production by using new home production data developed in Bridgman (2016). With this model and its estimation at hand, we are able to study the reaction of consumption shares in the U.S. to a supply shock in manufacturing and to a supply shock in services.

We compare our model's results with those obtained in the model without a home production sector. We find that while the response to a manufacturing shock is similar in the two models, a shock to the services sector has a substantially milder effect on consumption shares in the model with a home production sector. Quantitatively, the market service share rises only by $0.4 \%$ 
in the model with a home sector relative to $1.3 \%$ in the model without a home sector, after a $10 \%$ increase in the service price. Our results therefore indicate that, when predicting the effects of a sectoral shock to the composition of sectoral shares in the economy, one has to take into account home substitutability of the goods produced.

\section{Model}

This section presents a model of structural change with a home production sector, first proposed in Moro et al. (2017). There is a representative household and five types of good produced in this economy: four consumption goods (agriculture, manufacturing, market services, and home services) and one investment good. Preferences are given by

$u=\sum_{t=0}^{\infty} \beta^{t} \ln C_{t}$,

where $\beta$ is the subjective discount factor. The composite consumption index $C_{t}$ is defined as

$C_{t}=\left(\sum_{i=a, m, s}\left(\omega^{i}\right)^{\frac{1}{\sigma}}\left(c_{t}^{i}+\bar{c}^{i}\right)^{\frac{\sigma-1}{\sigma}}\right)^{\frac{\sigma}{\sigma-1}}$.

where $c_{t}^{i}$ denotes consumption of good $i \in\{a, m, s\}$. In (1), $\omega^{i}$ determines the weight of each good in household's preferences; $\bar{c}^{i}$ controls non-homotheticity in preferences; and $\sigma$ governs the elasticity of substitution between three goods. Service consumption is a composite of market services, $c_{t}^{s m}$, and home produced services, $c_{t}^{\text {sh }}$, as

$c_{t}^{s}=\left[\psi\left(c_{t}^{s m}\right)^{\frac{\gamma-1}{\gamma}}+(1-\psi)\left(c_{t}^{s h}+\bar{c}^{s h}\right)^{\frac{\gamma-1}{\gamma}}\right]^{\frac{\gamma}{\gamma-1}}$.

In (2), the parameter $\gamma$ governs the elasticity of substitution between market and home services and $\psi$ is the share parameter in the service aggregator. We allow for a different income elasticity between market and home services through the parameter $\bar{c}^{s h}$.

Each period, the household is endowed with $\bar{l}=1$ unit of labor that she splits into working time in the market, $l_{t}^{m k}$, paid at wage $w_{t}$ and working time at home, $l_{t}^{s h}$. Also, the household holds the capital stock $k_{t}$ in the economy, and decides how much to rent in the market, $k_{t}^{m k}$, at rate $r_{t}$, and how much to use in home production, $k_{t}^{s h}$. Then, the household's constraints are given by

$p_{t}^{a} c_{t}^{a}+p_{t}^{m} c_{t}^{m}+p_{t}^{s m} c_{t}^{s m}+k_{t+1}^{m k}-(1-\delta) k_{t}^{m k}+k_{t+1}^{s h}-(1-\delta) k_{t}^{s h}$

$=r_{t} k_{t}^{m k}+w_{t} l_{t}^{m k}$

$l_{t}^{m k}+l_{t}^{s h}=\bar{l}$,

where $p_{t}^{j}$ is the price of good $j \in\{a, m, s m\}$ and $\delta$ is the depreciation rate. We normalized the price of the investment goods to be equal to one. The total amount of capital is defined as

$k_{t} \equiv k_{t}^{m k}+k_{t}^{s h}$.

The household produces home services through the following technology,

$c_{t}^{s h}=A_{t}^{s h}\left(k_{t}^{s h}\right)^{\alpha}\left(l_{t}^{s h}\right)^{1-\alpha}$

There is a perfectly competitive firm in each market sector $j \in$ $\{a, m, s m\}$ with technology,

$Y_{t}^{j}=A_{t}^{j}\left(K_{t}^{j}\right)^{\alpha}\left(L_{t}^{j}\right)^{1-\alpha}$,

and a perfectly competitive firm operating in the investment good sector with technology,

$Y_{t}^{x}=A_{t}^{x}\left(K_{t}^{x}\right)^{\alpha}\left(L_{t}^{x}\right)^{1-\alpha}$.
Moro et al. (2017) show that the problem of the household can be split into an inter-temporal problem and an intra-temporal problem and that the latter is the one driving structural transformation. Following their approach, we obtain the set of the sectoral shares equations:

$$
\begin{aligned}
\frac{p_{t}^{a} c_{t}^{a}}{E_{t}} & =\frac{\left(p_{t}^{a}\right)^{1-\sigma} \omega^{a} \Phi_{t, 1}}{\Phi_{t, 2}}-\frac{p_{t}^{a} \bar{c}_{t}^{a}}{E_{t}}, \\
\frac{p_{t}^{m} c_{t}^{m}}{E_{t}} & =\frac{\left(p_{t}^{m}\right)^{1-\sigma} \omega^{m} \Phi_{t, 1}}{\Phi_{t, 2}}-\frac{p_{t}^{m} \bar{c}_{t}{ }^{m}}{E_{t}}, \\
\frac{p_{t}^{s m} c_{t}^{s m}}{E_{t}} & =\frac{\left(p_{t}^{s m}\right)^{1-\sigma} \omega^{s} \psi^{\sigma} \Omega_{t, 1}^{\frac{\sigma}{\gamma}-1} \Phi_{t, 1}}{\Phi_{t, 2}}-\frac{p_{t}^{s m} \Omega_{t, 1}^{-1} \bar{c}^{s}}{E_{t}}, \\
\frac{p^{s h} c^{s h}}{E} & =\frac{\left(p^{s h}\right)^{1-\sigma} \omega^{s 2}(1-\psi)^{\sigma} \Omega_{2}^{\frac{\sigma}{\gamma}-1} \Phi_{t, 1}}{\Phi_{t, 2}}-\frac{p^{s h} \Omega_{2}^{-1} \bar{c}^{s_{2}}}{E} .
\end{aligned}
$$

where $p_{t}^{s h}$ is the implicit price of the home good. ${ }^{1}$ The terms $\Phi_{t, 1}$ $\Phi_{t, 2}, \Omega_{t, 1}$ and $\Omega_{t, 2}$ in Eqs. (4), (5), (6) and (7) are defined as:

$$
\begin{aligned}
\Phi_{t, 1} \equiv & {\left[1+\frac{p_{t}^{a} \bar{c}^{a}+p_{t}^{m} \bar{c}^{m}+p_{t}^{s h} \bar{c}^{s h}+p_{t}^{s m} \Omega_{t, 1}^{-1} \bar{c}^{s}+p_{t}^{s h} \Omega_{t, 2}^{-1} \bar{c}^{s}}{E_{t}}\right], } \\
\Phi_{t, 2} \equiv & \left(p_{t}^{a}\right)^{1-\sigma} \omega^{a}+\left(p_{t}^{m}\right)^{1-\sigma} \omega^{m}+\left(p_{t}^{s m}\right)^{1-\sigma} \omega^{s} \psi^{\sigma} \Omega_{t, 1}^{\frac{\sigma}{\gamma}-1} \\
& +\left(p_{t}^{s h}\right)^{1-\sigma} \omega^{s}(1-\psi)^{\sigma} \Omega_{t, 2}^{\frac{\sigma}{\gamma}-1}, \\
\Omega_{t, 1} \equiv & {\left[\psi+(1-\psi)\left(\frac{1-\psi}{\psi}\right)^{\gamma-1}\left(\frac{p_{t}^{s m}}{p_{t}^{s h}}\right)^{\gamma-1}\right]^{\frac{\gamma}{\gamma-1}}, } \\
\Omega_{t, 2} \equiv & {\left[\psi\left(\frac{\psi}{1-\psi}\right)^{\gamma-1}\left(\frac{p_{t}^{s h}}{p_{t}^{s m}}\right)^{\gamma-1}+(1-\psi)\right]^{\frac{\gamma}{\gamma-1}} . }
\end{aligned}
$$

In the next section we use the share equations (4), (5), (6) and (7) to analyze how shocks to the prices of manufacturing and services affect the sectoral composition.

\section{Calibration}

There are nine parameters to be calibrated. To determine the parameter values, we follow the approach in the previous literature that estimates structural change models with U.S. value-added data. First, we set the value of the parameter $\sigma$ to zero, which governs the elasticity of substitution across agricultural good, manufacturing good, and aggregate services. Using the U.S. data from 1947 through 2010, Moro et al. (2017) estimate the structural transformation model with a home sector and find that $\sigma$ is close to zero. Similarly, Herrendorf, Rogerson, and Valentinyi (2013) (hereafter HRV) estimate $\sigma$ to be close zero in their three-sector model without a home sector. The remaining non-homothetic parameters $\left\{\bar{c}^{a}, \bar{c}^{s}, \bar{c}^{s h}\right\}$ and weight parameters $\left\{\omega^{a}, \omega^{m}, \omega^{s}, \psi\right\}$ are calibrated to the estimates in Moro et al. (2017).

Finally, $\gamma$ is the parameter most relevant to this paper's exercise, which governs the elasticity of substitution between market and home services. In the literature, one set of studies estimates the parameter $\gamma$ by using fluctuations of aggregate home hours over the business cycles (McGrattan et al., 1997; Chang and Schorfheide, 2003). Another set of studies, instead, uses household micro data for home hours (Rupert et al., 1995; Aguiar and Hurst, 2007). Moro et al. (2017) review this literature, and report the range of the estimates for the parameter $\gamma$. We follow the choice of the value in Moro et al. (2017), and set $\gamma$ to 2.3. Parameter values are report in Table 1.

1 See Moro et al. (2017) for the derivation. 
Table 1

Parameter values calibrated.

\begin{tabular}{|c|c|c|c|c|c|c|c|c|c|}
\hline Name & $\sigma$ & $\bar{c}^{a}$ & $\bar{c}^{s}$ & $\bar{c}^{s h}$ & $\omega^{a}$ & $\omega^{m}$ & $\omega^{s}$ & $\gamma$ & $\psi$ \\
\hline Value & 0.0 & -129.0 & 4360.8 & -5135.3 & $2.6 \times 10^{-3}$ & $15.7 \times 10^{-2}$ & $8.4 \times 10^{-2}$ & 2.3 & $62.5 \times 10^{-2}$ \\
\hline
\end{tabular}
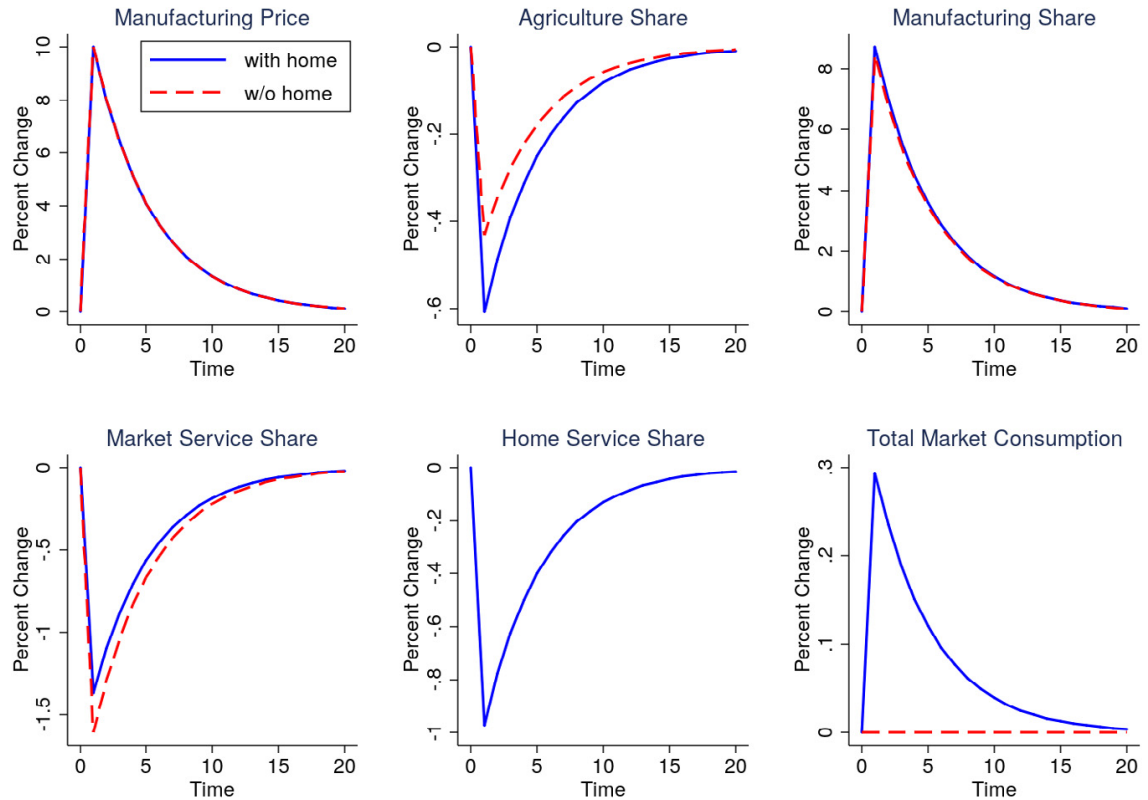

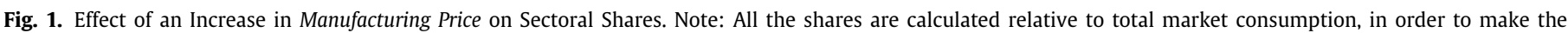
results in our model and HRV (2013) comparable.

\section{Response of the model to sectoral shocks}

We study how the calibrated model behaves when there is a shock to relative prices. We compare our model with the traditional structural transformation model in HRV (2013), in which there is no home production sector. Our model reduces to the three-sector model when $\psi$ is set to one. We set the parameter values of the three sector model to those in HRV (2013). ${ }^{2}$ In each model, we introduce a shock implying a $10 \%$ increase in the manufacturing good price or the market service price. These shocks can be considered as a negative productivity shock in either sector. We consider the year 2010 as the benchmark year, and set the pre-shock sectoral prices, $\left\{p_{t}^{a}, p_{t}^{m}, p_{t}^{s m}, p_{t}^{s h}\right\}$, and household's total extended consumption expenditure, $E_{t}$, to the values in that year. ${ }^{3}$ The corresponding levels of sectoral shares are: agriculture 0.009 , manufacturing 0.091 , market services 0.647 and home services 0.252 . We then simulate the movements of the sectoral shares in the economy after the shock hit. Figs. 1 and 2 report the percentage changes in the shares as a result of these experiments.

Comparing the responses of the two models to the price shocks, first note that, in both models, $\sigma$ is zero, meaning that the utility function takes a Leontief specification in terms of agriculture, manufacturing, and aggregate services. This, in the model without home production, implies that quantities in equilibrium are little affected by changes in prices, so that the share of manufacturing (or services) increases and the other shares decline after the rise in the price of manufacturing (or services). See the model without home in Figs. 1 and 2 on this point. This is

\footnotetext{
2 Specifically, we set the parameters of the three-sector model without a home sector to those of the specification "(2)" in Table 3 in HRV (2013). HRV (2013) find the parameter values by estimating their three-sector model with the U.S. data for the same time-period as that of Moro et al. (2017).

3 See Moro et al. (2017) for the complete description of the data construction and sources.
}

also true for the model with home production, when the shock is on the manufacturing price as shown by the model with home in Fig. 1.

When the shock is on the market service price, the result is different. As shown in Fig. 2, the rise in the share of market services becomes relatively smaller in the model with home than in the model without home because the household substitutes market services with home services in the former. Quantitatively, the market service share rises only by $0.4 \%$ in the model with home relative to $1.3 \%$ in the model without home. This substitution effect is also reflected in the decline of total consumption expenditure in the market as shown in the last panel in Fig. 2, which is in contrast with the increase observed in Fig. 1. As a result, the variations of all market shares are smaller in magnitude, compared to the case with no home production: the agricultural share changes by $+1.0 \%$ in the model with home and by $-2.1 \%$ in the model without home. The manufacturing share changes by $-2.4 \%$ in the model with home, while it changes by $-6.8 \%$ in the model without home.

Note that the share of agriculture reacts in opposite directions to the two shocks. After the manufacturing shock, the low elasticity of substitution implies that the share of all non-manufacturing types of consumption declines, because quantities react little, and the behavior of the share is driven by the relative prices. After a services shock, the non-homotheticity of preferences comes into play. As services represent a large fraction of consumption, this shock implies a substantial decline in the purchasing power of the consumer. As agriculture displays an income elasticity smaller than one, the household increases its consumption in response to a smaller purchasing power.

In summary, when there is a shock to the price of services, substitution between market and home services occurs. Therefore, our model exhibits a share movement which is substantially different from the traditional three-sector model in the previous literature. 

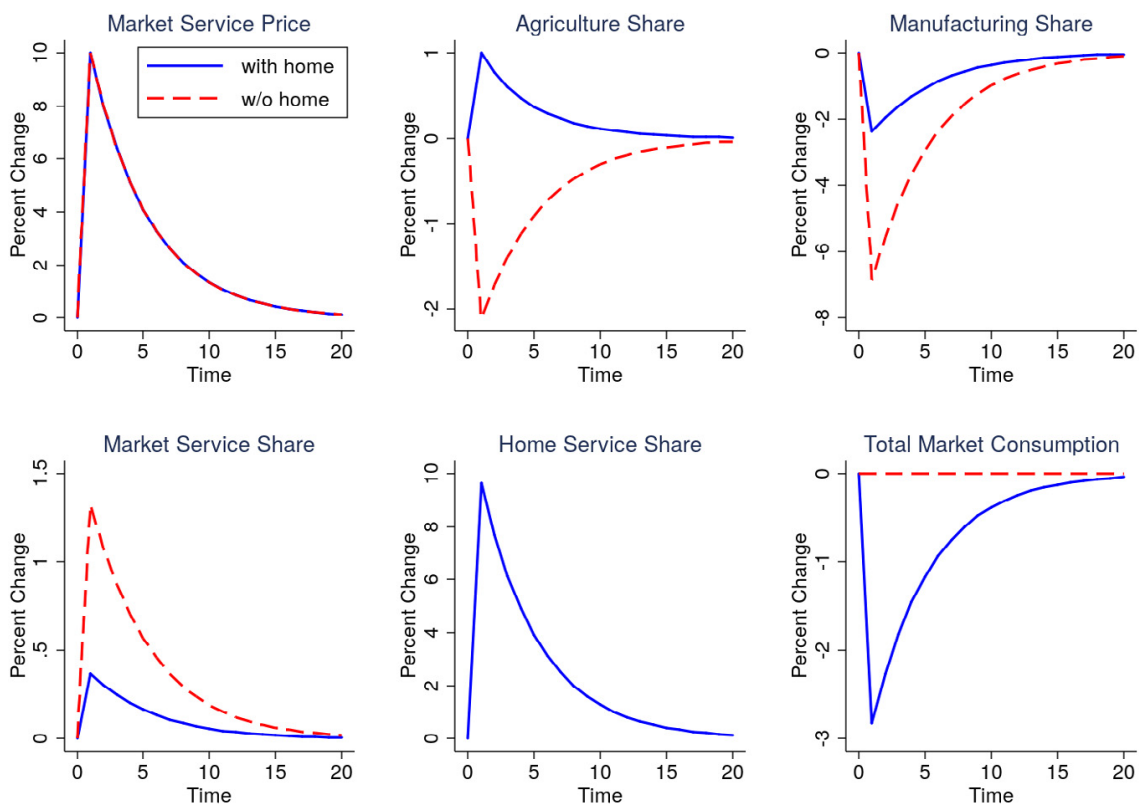

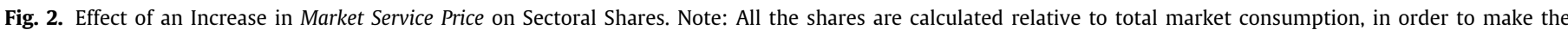
results in our model and HRV (2013) comparable.

\section{Conclusion}

We used a state of the art model of structural transformation with a home produced sector calibrated to the U.S. economy to show how market consumption shares are affected by manufacturing and service sectors' supply shocks. As home production is a substitute product for market services, a supply shock to the market service sector does not affect market sectoral composition to a large extent. The opposite occurs when a manufacturing shock hits. Our results of share movements also imply that, once the model is extended to a general equilibrium model framework, the patterns of relocation of capital and labor after a shock hits crucially depend on home substitutability of the goods produced in the sector.

\section{References}

Aguiar, M., Hurst, E., 2007. Measuring trends in leisure: The allocation of time over five decades. Q. J. Econ. 122 (3), 969-1006.

Benhabib, J., Rogerson, R., Wright, R., 1991. Homework in macroeconomics: Household production and aggregate fluctuations. J. Polit. Econ. 99 (6), 1166-1187.
Bridgman, B., 2016. Home productivity. J. Econom. Dynam. Control 71, 60-76. Chang, Y., Schorfheide, F., 2003. Labor-supply shifts and economic fluctuations. J. Monetary Econ. 50, 1751-1768.

Greenwood, J., Hercowitz, Z., 1991. The allocation of capital and time over the business cycle. J. Polit. Econ. 99 (6), 1188-1214.

Herrendorf, B., Rogerson, R., Valentinyi, Á., 2013. Two perspectives on preferences and structural transformation. Amer. Econ. Rev. 103 (7), 2752-2789.

McGrattan, E.R., Rogerson, R., Wright, R., 1997. An equilibrium model of the business cycle with household production and fiscal policy. Internat. Econom. Rev. 267-290.

Moro, A., Moslehi, S., Tanaka, S., 2017. Does home production drive structural transformation?. Amer. Econ. J.: Macroecon. 9 (3), 116-146.

Ngai, L., Petrongolo, B., 2017. Gender gaps and the rise of the service economy. Amer. Econ. J.: Macroecon. 9 (4), 1-44.

Ngai, L., Pissarides, C.A., 2008. Trends in hours and economic growth. Rev. Econ. Dyn. 11 (2), 239-256.

Rendall, M., 2018. Female market work, tax regimes, and the rise of the service sector. Rev. Econ. Dyn. 28, 269-289.

Rogerson, R., 2008. Structural transformation and the deterioration of european labor market outcomes. J. Polit. Econ. 116 (2), 235-259.

Rupert, P., Rogerson, R., Wright, R., 1995. Estimating substitution elasticities in household production models. Econom. Theory 6 (1), 179-193. 